\title{
O uso de Métodos Ágeis no ensino de Métodos Ágeis
}

\author{
Avelino Ferreira Gomes Filho ${ }^{1}$ \\ Carlos Felippe Cardoso de Resende ${ }^{2}$ \\ Rodrigo de Toledo ${ }^{3}$
}

Data de submissão: 08.07.2015

Data de aceitação: 01.11.2015

\begin{abstract}
Resumo: No Curso de Métodos Ágeis oferecido aos alunos de graduação da Universidade Federal do Rio de Janeiro, os professores decidiram que o modelo tradicional de educação não seria o mais adequado para o ensino de um assunto que quebra tantos paradigmas. Este artigo apresenta os quatro anos de experiência dos professores aplicando conceitos ágeis na disciplina de Métodos Ágeis para os alunos de graduação do curso de Informática. Nosso objetivo é demonstrar como o uso desses conceitos ajudou a criar um ambiente de aprendizagem estimulante e eficaz.
\end{abstract}

\begin{abstract}
In the Agile Methods Discipline offered to undergraduate students of the Universidade Federal do Rio de Janeiro, the teachers decided that the traditional model of education would not be the most suitable way of teaching a subject that breaks so many paradigms. This paper presents the four years experience of the teachers applying agile concepts in the Agile Methods discipline. Our goal is to report how they use these concepts to create a stimulating and effective learning environment.
\end{abstract}

\footnotetext{
${ }^{1}$ Programa de Pós-Graduação de Informática - Universidade Federal do Rio de Janeiro avelino.filho@ppgi.ufrj.br

${ }^{2}$ Universidade Federal do Rio de Janeiro

cfceppgi.ufrj.br

${ }^{3}$ Departamento de Ciência da Computação - Universidade Federal do Rio de Janeiro rtoledoedcc.ufrj.br
} 


\section{Introdução}

Compartilhar, construir conhecimento e tornar alunos agentes ativos do ensino não é uma tarefa fácil de ser realizada. Utilizar práticas comuns, em que o professor transmite seu conhecimento para a turma que passivamente assiste as aulas e no final do período é avaliada por uma prova, pode não ser o meio mais estimulante para engajar os alunos no aprendizado.

Na disciplina de Métodos Ágeis do curso de Graduação em Informática da Universidade Federal do Rio de Janeiro, os professores decidiram que o modelo tradicional de ensino não seria o mais adequado para um tema que representa quebras de vários paradigmas. Eles decidiram aplicar valores e princípios ágeis não só no conteúdo da matéria, como também na forma como a disciplina é realizada.

Este artigo apresenta como os Métodos Ágeis de Desenvolvimento de Software foram aplicados ao contexto de educação e aprendizado para criar um Método de Ensino que instancia e utiliza as teorias de aprendizagem Social e Experiencial. No final do trabalho, é apresentado uma avaliação que busca verificar se o Método de Ensino adotado é capaz de construir um ambiente colaborativo, estimulante e desafiador e com isso contribuir com a construção de conhecimento aplicável à futura vida profissional dos alunos.

Esse trabalho está assim estruturado: O referencial teórico é descrito na Seção 2. A Seção 3 apresenta como os conceitos ágeis se relacionam com as teorias de aprendizagem para aplicação na sala de aula. A Seção 4 apresenta como os alunos são avaliados na disciplina. As Seções 5, 6 e 7 apresentam a hipótese, método e resultado da avaliação disciplina. Por fim, na seção 8 apresentamos a conclusão do trabalho.

\section{Referencial Teórico}

\subsection{Métodos Ágeis}

Durante a disciplina apresentada nesse trabalho, os alunos têm contato com uma série de frameworks, métodos, práticas e sistemas compatíveis com os valores e princípios propostos no Manifesto Ágil. Essa subseção apresenta sucintamente o Manifesto Ágil e o conjunto técnicas ágeis que são apresentadas durante o período letivo.

Métodos Ágeis não devem ser entendidos como modelos únicos e prescritivos para o desenvolvimento de software. Na verdade, o termo serve como um guarda-chuva para um extenso conjunto de metodologias, práticas, frameworks e técnicas compatíveis com os valores e princípios descritos no Manifesto Ágil [1,2]. Esse manifesto apresenta quatro valores e doze princípios considerados essenciais para a produção de software de alto valor agregado em curtos ciclos de iteração. 
Das técnicas ágeis mais aplicadas na disciplina, a mais importante é o Scrum [3]. Ele é um Framework que define processo, ciclos de inspeção e adaptação, papéis e artefatos básicos para o desenvolvimento de software. Como todo arcabouço, ele restringe-se na descrição de conceitos abstratos que devem ser instanciados para contextos específicos. De todos os frameworks, métodos e processos compatíveis com o Manifesto Ágil, o Scrum é o mais utilizado pelo mercado de desenvolvimento de software [4,5]. O Framework já foi utilizado em diversos trabalhos que buscavam introduzir Métodos Ágeis de Desenvolvimento de Software como base para um processo de ensino [6-8].

O eXtreme Programming (XP) [9] é um método utilizado em diversos momentos da disciplina. Assim como o Scrum, o XP não descreve exatamente como fazer. Entretanto, este é considerado um pouco mais prescritivo. Ele estende os valores e princípios do Manifesto Ágil acrescentando foco maior no relacionamento e atitudes dos envolvidos na construção do software e apresenta práticas que podem ser utilizadas para aumentar a eficácia e agilidade de um time de desenvolvimento de software. Esse método já foi aplicado academicamente na USP [10,11] e também pelo Professor Vinícius Teles na UFRJ entre 2001 e 2003 [12]

O Lean Kanban [13] é um método utilizado para aumentar a performance de entrega de software por um time de desenvolvimento. Sua origem é o Sistema Kanban [14] utilizado pela Toyota na produção just-in-time de veículos. Ele foi adaptado para a indústria de software e na disciplina ele é mais utilizado durante o Sabadágil descrito na Subseção 3.5.

Durante o semestre, é esperado que os alunos desenvolvam um software e o disponibilizem na internet e colham métricas de utilização e feedback de usuários reais. O problema resolvido pelo software deve ser relevante e despertar o interesse de pessoas que não estão envolvidas na disciplina. Para testar ideias de forma rápida e objetiva, os alunos utilizam técnicas de Lean Startup [15]. Esse método tem como objetivo principal auxiliar novos empreendedores a descartar rapidamente ideias ruins e compreender o mercado em que eles atuarão.

\subsection{Teorias de Aprendizagem}

O Método de Ensino apresentado no trabalho baseia-se em diversas teorias de aprendizagem. Nessa subseção apresentamos sucintamente algumas das teorias de ensino utilizadas.

Para essa disciplina os professores utilizam uma abordagem construtivista em que os alunos passam a ser sujeitos ativos e principais responsáveis pelo aprendizado [16]. Há uma expectativa que os alunos consigam aplicar o conhecimento teórico em problemas práticos e também que eles façam uma série de experimento através de interações sociais [17]. Não há trabalho nem avaliação individual. O bom andamento do período depende de uma combinação de estímulos extrínsecos e intrínsecos de professores e alunos que além de aplicar o conhecimento, são os responsáveis por ditar o ritmo e os itens de aprendizagem que serão 
apresentados e experimentados.

A Teoria de Aprendizagem Social Cognitiva [18] é muito relevante para o Método de Ensino aplicado. O autor escreve que o aprendizado decorre da modelação social operada através de uma rede de influências e limitações socioestruturais (alunos, professores e contexto da disciplina). O autor destaca a importância do Feedback instrutivo e reflexão sobre as ações para aperfeiçoamento dos sujeitos sociais (alunos e professores).

A aprendizagem experiencial [19] é também presente em toda a disciplina. Nessa proposta de aprendizagem, o processo de significação dos itens dá-se através da experiência direta e reflexão das ações [20].

Por fim, a disciplina adota ações de Aprendizagem Democrática [21]. Os professores procuram tornar-se uma fonte efetiva de autoridade. Respeitada, aproveitada e não impositiva [22].

\subsection{Trabalhos Relacionados}

O uso de Métodos Ágeis para o Ensino foi abordado por Kamat [23] ao apresentar o Manifesto Ágil para o Ensino Superior. Assim como no Manifesto Ágil original [1], o autor afirma que é necessário que o ensino siga quatro valores fundamentais: Professores e alunos mais que administração e infraestrutura; Competência e colaboração mais que conformidade e competição; Empregabilidade e empreendedorismo mais que ementa e marcos; Atitude e habilidade de aprendizagem mais que aptidão e diploma. Segundo o autor, é necessário aplicar esses valores aos processos de ensino e aprendizagem, avaliação de alunos e professores e processos administrativos.

Kamat e Sardessai [24] apresentam um estudo de caso sobre o emprego do Manifesto Ágil para Educação Superior no Curso de Ciência da Computação da Universidade de Goa na Índia. Na avaliação dos autores que utilizou técnicas de Pré-teste e Pós-teste com Alfa de Cronbach de 0,89, os alunos apresentaram um ligeiro aperfeiçoamento de aprendizado. E um baixo índice de abandono, menor do que $1 \%$.

Outro estudo importante nessa área foi realizado por Grimheden [25]. Nele, o autor apresenta o uso do Scrum para auxiliar o processo de aprendizagem de alunos da graduação. O autor avalia como elevados o comprometimento dos alunos e a satisfação dos alunos quando trabalham com um Método de Ensino baseado no supracitado framework.

Já Stettina et al. [26] apresentam um quase-experimento em que eles aplicam algumas práticas baseadas no Scrum no processo de ensino. Segundo os autores, os times que aplicam as práticas ágeis mostram maior satisfação no aprendizado do que aqueles que não aplicaram tais práticas. 
Um Método baseado no Lean Kanban foi descrito e estudado em contexto de aprendizado por Anderson et al. [13]. Eles escrevem como a abordagem prática, experimental e reflexiva auxilia os praticantes de Lean Kanban a construir o conhecimento e aprimorar seus processos de construção de software. Willeke [27] vai além e escreve que o método Lean deve ser aplicado à toda universidade.

Por fim, o trabalho de Kropp e Meier [28] é de especial importância, pois avaliam a necessidade de um processo de ensino e aprendizagem baseado nos valores e princípios ágeis. Segundo os autores, esses modelos de ensino devem suprir carências percebidas pela indústria de software: Ter profissionais resilientes, capazes de se adaptar a mudanças e com conhecimento em Métodos Ágeis para gestão ou execução de projetos. Os autores também apresentam um método totalmente baseado nos mesmos valores e princípios. Também avaliam positivamente através de questionários respondidos pelos alunos, o método de ensino por eles empregado.

\section{A Disciplina de Métodos Ágeis}

\subsection{Seleção de Alunos}

O ensino de Métodos Ágeis e seus princípios democráticos começa antes mesmo da primeira aula. Em um período, apenas vinte alunos participam da matéria por restrição dos próprios professores. Porém, todos os anos, a quantidade de interessados em cursá-la é mais que o dobro do número de vagas. Os professores decidiram então aplicar os princípios e valores dos Métodos Ágeis como auto-organização, transparência e respeito ao próximo [1, 3,29] já na seleção dos alunos.

A seleção de alunos é fundamentada na Aprendizagem Democrática. Os critérios, métodos e ações de seleção são elaboradas pelos próprios alunos e os professores desempenham o papel de autoridade de apoio, não impositiva com o objetivo apenas de auxiliar o processo $[21,22]$.

Inicialmente, eles se reúnem com todos os interessados e juntos decidem os critérios que utilizarão para seleção. Estes devem ser simples, relevantes e acordados com todos os participantes do processo, por exemplo: demonstrar capacidade de trabalhar em grupo, ter conhecimento sobre linguagens de programação, poder comparecer às aulas pontualmente, não estar cursando matérias que reconhecidamente tomam muito tempo de estudo do aluno, entre outros.

Uma vez que os critérios tenham sido definidos, os dez alunos mais antigos do curso e interessados na matéria são selecionados para desempenhar o papel de entrevistador. Os dez alunos formam cinco duplas e cada dupla deve entrevistar e selecionar os demais alunos 
interessados para cursar a disciplina do período, sempre observando os critérios decididos por todos. Para que os alunos comecem praticando a auto-organização, os professores não interferem na seleção de alunos. Eles estão disponíveis para ajudar os entrevistadores em caso de dúvidas. Para demonstrar respeito ao próximo e transparência, no final da seleção, todos os alunos entrevistados recebem presencialmente feedback informando os motivos que levaram a sua aprovação ou reprovação na seleção.

\subsection{Ensino Baseado em Problemas Reais}

As aulas têm como objetivo fazer com que os alunos adquiram conhecimento sobre Métodos Ágeis através da experiência prática e reflexão das suas ações. Esse modelo é uma implementação do Aprendizado Baseado em Problemas [30].

No início do período, os professores pedem para que os alunos pensem em problemas que eles percebem no dia a dia e que eles poderiam resolver através de um software. As únicas restrições são: a) deve ser um problema real; b) pode ser resolvido por software; c) deve ser útil para a comunidade. O tema é de livre escolha: transporte, serviços, estágios, alimentação, confraternizações e etc.

Os alunos são divididos em duplas e utilizam as técnicas de Lean Startup [15] para avaliar quais os melhores problemas e descartar aqueles que se mostrem inviáveis, desinteressantes ou que já tenham sido resolvidos por algum produto. A avaliação busca responder se o problema é um problema de fato, se há usuários potenciais para o produto e na viabilidade do mesmo. Nesse momento são utilizadas técnicas de Métodos Ágeis como o Validation Board [31] e jogos de inovação [32] com o intuito de verificar se a ideia que eles tiveram é ou não é viável e se tem potencial de aceitação.

O Validation Board é uma ferramenta do Lean Startup que serve para gerar aprendizado sobre uma hipótese através da validação de ideias. Nesta ferramenta, os alunos definem algumas suposições sobre o problema que eles querem tratar, os potenciais clientes e definem os experimentos que serão feitos para verificar a suposição. Ele auxilia os grupos a acompanhar a evolução do trabalho e a manter o foco no essencial para resolver o problema imaginado. Com ele, os alunos conseguem visualizar graficamente se suas hipóteses são válidas. Ele também ajuda os alunos a "pivotar" as hipóteses inválidas [31].

"Pivotar"é o termo utilizado para correção do curso das ações de forma estruturada com o intuito de testar uma nova hipótese sobre o produto ou estratégia [15].

Após criar o Validation Board, cada dupla apresenta sua avaliação e os alunos decidem quais irão para a votação. Na votação, três problemas são selecionados e esses problemas "puxarão" os conceitos de Métodos Ágeis através da abordagem experiencial [19] conforme será descrito na subseção 3.3. 
Os três problemas selecionados desencadearão os trabalhos em grupo. Esses trabalhos têm como objetivo a construção e disponibilização de um software que resolva o problema. As aulas são divididas em temas e cada um destes é uma parte do conhecimento de Métodos Ágeis de Desenvolvimento de Software que agrupa um conjunto de itens de aprendizagem. Um tema pode ser trabalhado em uma ou diversas aulas, dependendo da quantidade de itens ou da vontade dos alunos em compreendê-lo melhor. Eles contêm o conteúdo necessário para que os alunos superem uma etapa do projeto desde aquelas pré-projeto como a compreensão de valores e princípios, validação de ideias, passando pela gestão do projeto com Scrum e Lean Kanban, técnicas de construção do XP e Qualidade até etapas pós-projetos como a coleta e uso de métricas para tomada de decisão.

Os itens de aprendizagem são tópicos que compõem o tema. Por exemplo, para que um aluno compreenda o tema Framework Scrum, ele deve compreender os diversos itens de aprendizagem relacionados ao Framework. São eles: Pilares do Scrum, Papéis, ciclo de vida de desenvolvimento, processo de desenvolvimento, Sprint, todas as cerimônias: Sprint Planning 1, Sprint Planning 2, Daily Meeting, Review e Retrospectiva, entre outros. A Tabela 1 apresenta a lista com os temas de aula e a quantidade de itens que compõem cada tema em média.

\begin{tabular}{|l|r|}
\hline \multicolumn{1}{|c|}{ Tema } & Quantidade de Itens de Aprendizagem \\
\hline eXtreme Programming (XP) & $\mathbf{8}$ \\
\hline Lean Kanban & $\mathbf{1 5}$ \\
\hline Lean Startup & $\mathbf{6}$ \\
\hline Métricas & $\mathbf{8}$ \\
\hline Personas & $\mathbf{1}$ \\
\hline Qualidade & $\mathbf{1 6}$ \\
\hline Quebra de Paradigmas & $\mathbf{6}$ \\
\hline Scrum & $\mathbf{2 4}$ \\
\hline Valores e Princípios & $\mathbf{6}$ \\
\hline Total & $\mathbf{9 0}$ \\
\hline
\end{tabular}

Tabela 1: Quantidade de Itens de Aprendizagem por Tema

A Figura 1 apresenta o ciclo da disciplina. O problema gera uma hipótese de solução que deve atender não só às necessidades dos usuários como também a necessidade de aprendizado imaginada pelos professores. Os alunos passam a desempenhar o papel de Product Owner (P.O.) [3]. Inicialmente os alunos pensam quais seriam as Personas que utilizariam o software. Essas personas são os possíveis perfis de usuário que utilizarão o sistema [33]. Definidas as Personas, os alunos começam a descrever as funcionalidades que mais agregam valor para os possíveis usuários. Cada funcionalidade é escrita no formato de User Story [33] que a apresenta de forma bastante sucinta e do ponto de vista do negócio, sem jargões técni- 
cos. O P.O. também deve valorar cada User Story indicando o quanto a transformação desta em software irá gerar de ganho para o negócio. Todas as User Stories são colocadas em um artefato chamado Product Backlog. Cada User Story ganha um vínculo com: a Persona que será diretamente atingida quando ela for disponibilizada no software, o esforço estimado pelo grupo para realizar a implementação. Uma dinâmica para a construção do Product Backlog é a Prune the Product Tree [32], como na Figura 2.

A construção do Software é acompanhada através do Framework Scrum ao longo do período em seções de Coding Dojo (Ver Subseção 3.3) e no Sabadágil (Subseção 3.5). Durante o Sabadágil, a construção do produto adota o modelo Lean Kanban e o resultado é avaliado pelos alunos dos outros grupos, professores e profissionais externos convidados pelos professores para participar do evento.

Após o desenvolvimento, os alunos colocam o produto em produção, disponibilizando

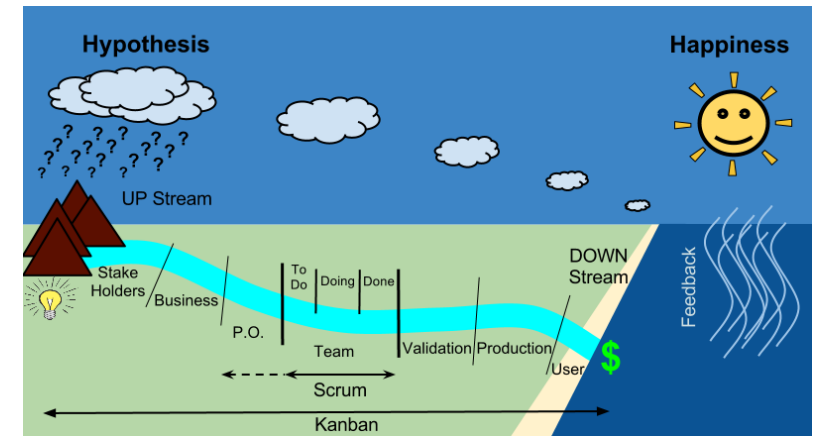

Figura 1: Ciclo de Lean Startup que serve como base para a disciplina de Métodos Ágeis.
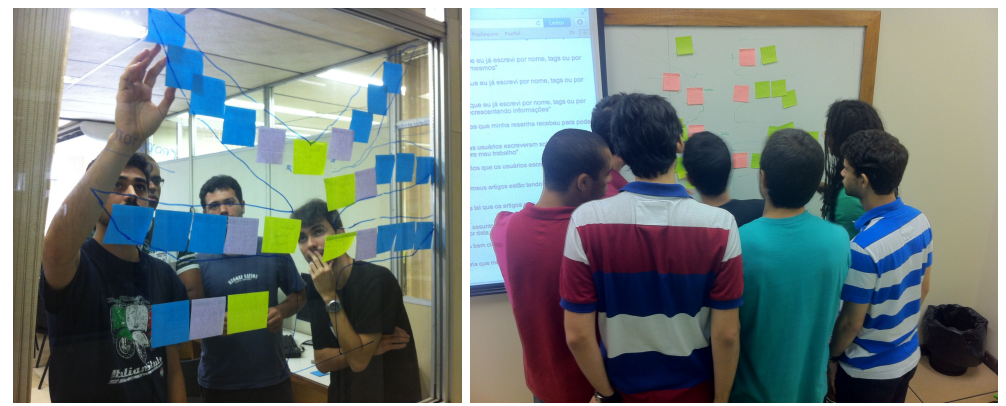

Figura 2: Alunos fazendo uso da técnica de Prune the Product Tree para a construção do Backlog. 
o software na internet ou em alguma plataforma de distribuição como a Apple Store ou Google Play.

No final de cada etapa da construção do software os alunos devem refletir sobre as ações que eles tomaram. Cada grupo discute internamente se a experiência foi interessante, $o$ que podia ser melhorado e se há alguma coisa impedindo o andamento do trabalho. Todos os alunos são expostos aos mesmos itens de aprendizagem na sala de aula, porém os professores não interferem como os alunos utilizam esses itens nos seus trabalhos. Os princípios da aprendizagem democrática, experiencial e social são aplicados durante todo o período.

\subsection{Ensino Puxado}

Grande parte do conteúdo da matéria é "puxada" pela prática e experiência que os alunos adquirem ao resolver problemas reais. Espera-se que esse modelo auxilie os alunos a compreender melhor os temas que estão sendo apresentados pelos professores, promova a reflexão constante e colaborativa sobre o resultado das ações por eles tomadas e consequentemente aprimore continuamente o aprendizado de todos os envolvidos [30,34].

Para que seja possível percorrer as etapas da aprendizagem experiencial [19], a aplicação do ensino puxado divide-se em quatro etapas. Inicialmente, os professores apresentam sucintamente o tema para os alunos. O tema é acompanhado de um problema real que deverá ser resolvido na aula (dinâmica). Em seguida, os alunos em conjunto tentam resolver o problema aplicando e desenvolvendo aquele conhecimento sucinto passado pelos professores. Após essa etapa, os alunos e professores refletem e discutem sobre o que foi realizado, as soluções aplicadas e as dúvidas que surgiram. De posse dessas informações, os professores então apresentam todo o conhecimento teórico sobre o tema.

Um exemplo desse ensino puxado acontece na aula cujo tema é Validação de Ideias. Como descrito na subseção 3.2, os alunos, no início do período devem pensar em um problema real que os afete e sua solução através de um software. Nessa aula específica, os professores questionam como os alunos fariam para avaliar se o software que eles imaginam tem potencial para resolver o problema e ser utilizado por usuários reais sem implementar uma linha de código e gastando muito pouco tempo. Os professores apresentam sucintamente o Validation Board e como ele funciona.

Os alunos utilizam essa ferramenta e chegam às suas soluções e questionamentos. Após a experiência prática e reflexão em conjunto, os professores apresentam toda a teoria sobre a origem desse quadro desde o Business Model Canvas, conceitos sobre Pivotar [15] e métricas de software.

Outra forma que os professores encontraram para aplicar o ensino puxado foi através de seções de programação projetada, conhecidas como Coding Dojo [35]. Elas têm como 
objetivo criar um ambiente colaborativo de aprendizado contínuo. Funcionam através de ciclos curtíssimos em que os alunos são convidados a resolver um problema em conjunto. Uma seção de Coding Dojo dura exatamente uma aula. Ao longo do período letivo, os professores aproveitam essas seções para puxar a teoria sobre Test-driven Development [36], Integração Contínua, Injeção de Dependência, Teste em Banco de Dados, etc.

\subsection{Melhoria Contínua da Disciplina}

Uma das grandes preocupações dos professores é aprimorar continuamente o curso, não só de um período como também para as turmas vindouras. Eles utilizam feedback constante dos próprios alunos em seções que acontecem no final da aula. Para tal, os professores e alunos fazem a reunião de lições aprendidas no dia. Essas lições devem responder a duas questões para auxiliar o ensino puxado: O que aprendemos hoje? O que gostaríamos de ter aprendido? E também duas questões para a melhoria contínua baseadas no Scrum [3]: O que foi bom e devemos continuar fazendo? O que podemos melhorar? Com isso os professores também conseguem uma maior participação dos alunos na disciplina, pois esses sentem-se responsáveis pelo caminho que eles mesmos escolhem.

Além de aperfeiçoar a disciplina, essa prática auxilia a execução da reflexão experiencial. É um momento de síntese das ideias apresentadas durante o período e definem o ritmo e andamento da disciplina.

Um exemplo dessas lições aprendidas dado pela turma de 2014 na aula cujo tema foi Produtos Enxutos. O que aprendemos: "Pivotagem; eXtreme eXperience; primeiro falar do problema e depois falar da solução; não existem requisitos, mas hipóteses; Minimum Viable Product". O que aprendemos não aprendemos e gostaríamos de ter aprendido: "Fórmula do Alisson Vale sobre redução do tempo entre a hipótese e o feedback dos usuários; Quadro de Validação de Ideias; Business Model Canvas". O que foi bom: "Horário da aula; quebrar paradigmas; aula focada". O que podemos melhorar: "projetor está com problema, horário de chegada dos alunos". Essa retrospectiva é sempre anotada em um bloco de notas virtual e compartilhado (http://dontpad.com/ufrjagil).

\subsection{Sabadágil}

O aprendizado acadêmico é muito importante, porém os futuros profissionais estarão sujeitos a diversas outras experiências quando chegarem ao ambiente corporativo. Pressão por prazos, mudanças de escopo, negociação constante, etc. Pensando nisso, os professores desenvolveram o Sabadágil. Um evento em que os alunos em um único dia e em iterações muito curtas implementam as funcionalidades essenciais do software que eles vêm trabalhando durante o curso. A expectativa é que este evento proporcione aprendizado acelerado dos alunos. Assim como as seções de Coding Dojo descritas no item 3.3, objetivo principal 
do evento não é a criação do software, mas sim a experiência e a reflexão que os alunos fazem ao aplicar o conhecimento adquirido até o momento em um contexto bem próximo ao que eles vivenciarão no mercado de trabalho.

O Sabadágil é um evento que ocorre uma vez no final de cada período, sempre aos sábados, daí o seu nome. O nível de comparecimento de alunos é muito alto. Nas quatro edições realizadas apenas um aluno faltou.

O evento conta também com profissionais que possuem reconhecida competência no uso de Métodos Ágeis no seu trabalho. São pessoas externas à universidade convidadas para desempenhar os papéis de Product Owner e Scrum Master [3]. O Product Owner foi descrito na subseção 3.2, já o segundo papel é o responsável por proteger o time de interferências, impedimentos, além de assegurar que o processo, incluindo as reuniões de apresentação e retrospectivas, funcione corretamente. Também são convidados outros profissionais com grande experiência em Métodos Ágeis para desempenhar o papel de Agile Coach [37]. Esses têm como principal objetivo servirem de tutores para os Product Owners e Scrum Masters nas realizações de suas ações. Essa aproximação de pessoas do mercado com os alunos da graduação é feita para que compartilhem suas experiências.

Seguindo a proposta do Lean-startup apresentada na Figura 1, o Sabadágil implementa o processo simples do framework Scrum (To do, Doing e Done) [3] para controlar a execução das User Stories. Cada grupo tem uma sala disponível, com tomadas para notebooks, quadro branco, lanches e qualquer material que o grupo ou os profissionais externos tenham trazido. Os profissionais são divididos e alocados conforme interesse e concordância do grupo.

Uma vez que o ambiente esteja preparado, a primeira coisa que o grupo faz é apresentar a visão do produto no formato de Elevator Test [38], as Personas e as User Stories para os participantes externos que desempenham os papéis de Product Owner e Scrum Master. Após a explicação, os participantes externos podem fazer perguntas e ponderações sobre o que lhes foi apresentado. Quando todas as dúvidas forem resolvidas, o desenvolvimento do produto começa segundo a priorização das User Stories. As iterações acontecem no formato de Sprint com 1h30 de duração. No final de cada Sprint o grupo deve apresentar o software para o Product Owner que poderá aceitar ou reprovar o resultado da iteração, além disso o Product Owner pode fazer qualquer mudança que julgar necessário nas User Stories (inclusão, alteração e exclusão). São realizadas quatro iterações durante o dia e no final, espera-se que o grupo tenha implementado o que foi definido como Minimum Viable Product (MVP) que são as User Stories essenciais para validar se a ideia que eles tiveram no início do período é ou não viável, se desperta o interesse de usuários reais e se consegue resolver o problema inicialmente imaginado. A escolha do MVP faz parte da nota do aluno, no geral são apenas as quatro ou cinco User Stories com o maior valor agregado para os possíveis usuários. $\mathrm{O}$ resultado do dia é apresentado para toda a turma e caso seja aprovado pelo Product Owner do grupo, ele é disponibilizado na internet para receber feedback dos usuários reais. Durante 
o evento, os times fazem uso de visibilidade e políticas explícitas do processo, práticas advindas do Kanban, ao explicitar as várias etapas e suas tarefas através de post-its no quadro do time.

Após o evento, o produto é disponibilizado para o público externo. É esperado que os alunos consigam usuários reais com o objetivo de colher feedback de pessoas que até então desconheciam os produtos. Também é desejável que os alunos colham métricas de utilização e possam adaptar o software ao uso real. As métricas podem ser usadas para obter feedback sobre o uso (quantidade e frequência de uso das funcionalidades, cliques na aplicação, buscas realizadas na aplicação), sobre a receptividade (quantidade de visitantes e visitas, opt-in e opt-out tempo de retenção, quantidade de downloads (Aplicações Móveis)), sobre o negócio (palavras que se buscadas no Google e acham o produto, origem das visitas), sobre aspectos técnicos (velocidade do acesso), etc.

O Sabadágil é a dinâmica mais importante da disciplina que permite em um só dia que os alunos tenham contato não só com os Métodos Ágeis como também permite a experiência de múltiplas teorias e práticas de aprendizagem. Utilizando a Taxonomia de Bloom revisada [39], durante o evento, os alunos podem chegar até o $5^{\circ}$ nível do domínio cognitivo, a Avaliação. Neste momento, eles são capazes de avaliar e escolher dentre os diversos itens de aprendizados que lhes foram apresentados durante o período o qual melhor se adéqua a uma determinada situação que acontece durante o evento.

\section{Avaliação dos alunos}

Essa disciplina não tem prova e os professores procuraram criar critérios de avaliação compatíveis com os valores e princípios ágeis. O peso que cada critério varia de período para período, pois são decididos pelos alunos em conjunto com os professores no final do período. Os critérios atuais são: Pré-Sabadágil, Sabadágil, Pós-Sabadágil, Minutagem, Auto Avaliação, Avaliação $360^{\circ}$ e Nota Cruzada. As subseções abaixo apresentam cada um dos critérios e como eles são realizados.

\subsection{Pré-Sabadágil}

O critério Pré-Sabadágil objetiva fazer com que os alunos desenvolvam as habilidades de percepção, análise de cenário, síntese e economicidade antes do início da implementação do software. Uma nota é atribuída pelos professores para cada um dos grupos e ela corresponde ao desempenho do grupo na fase inicial de criação do software antes do início da implementação. Esse critério é composto pelo correto uso de três subcritérios: Validation Board, a criação do MVP e o uso de Técnicas de Desenvolvimento Ágil que auxiliam o grupo a desenvolver o software com alto valor agregado e qualidade no curto espaço de 
tempo disponível para o curso.

No subcritério do Validation Board (apresentado na subseção 3.3) os professores buscam evidências de que os grupos foram capazes de compreender o problema imaginado, criar hipóteses relevantes para a solução desse problema e avaliar essas hipóteses antes do início da implementação. Eles verificam também se os alunos conseguiram "pivotar" de forma adequada as hipóteses que se mostraram inválidas.

O MVP, conforme mencionado na subseção 3.5, é o conjunto mínimo de User Stories que serve para avaliar se a solução de software é capaz de resolver o problema. Como o grupo tem menos de um semestre para implementar a solução e realizar essa avaliação, é fundamental que eles sejam capazes de priorizar apenas as User Stories mais relevantes. Nesse subcritério, todos os grupos começam com a nota dez. Para cada User Story que o professor achar desnecessária, o grupo perde um ponto. O grupo também perde um ponto para cada User Story que esteja muito abrangente (épico) ou caso o grupo tenha sido demasiadamente enxuto e seja necessário incluir novas User Stories.

No subcritério Técnicas de Desenvolvimento Ágil os professores avaliam se os alunos utilizam ferramentas que auxiliem o desenvolvimento de software. São as ferramentas de controle de versões, testes automatizados, integração contínua e descrição e controle do Product Backlog. Eles também avaliam se os alunos foram capazes de desenvolver o Hello World do software. O Hello World seve para que os alunos provem que são capazes de utilizar as plataformas, linguagens de programação, APIs e frameworks que serão utilizados na construção do software durante o Sabadágil.

\subsection{Sabadágil}

A nota do Sabadágil é atribuída pelos professores para todos os grupos. Ela procura expressar o desempenho dos alunos na aplicação dos métodos ágeis durante a construção do software. Os professores avaliam Quatro Domínios de Conhecimento da Agilidade, são eles: Negócio, Cultural, Organizacional e Técnico [40].

No domínio de Negócio os professores avaliam se o grupo foi capaz de priorizar as User Stories mais relevantes no momento do desenvolvimento, se eles foram capazes de fazer releases durante o evento, entre outros. Esse critério também leva em conta se os alunos conseguiram implementar pelo menos o MVP durante o Sabadágil. No domínio Cultural eles observam se o grupo conseguiu aplicar a melhoria contínua do processo ou produto, se os alunos conseguem resolver conflitos sozinhos, se há auto-organização e se há colaboração entre o grupo e do grupo com o Product Owner e Scrum Master convidado. No domínio Organizacional, é avaliada a capacidade do grupo na utilização dos métodos, frameworks e práticas que foram apresentadas durante as aulas. O grupo deve apresentar um processo de desenvolvimento, ferramentas de transparência e técnicas capazes de demonstrar a evolução 
do produto. Por fim, no domínio Técnico os alunos devem demonstrar a aplicação de técnicas ágeis como Automação de tarefas repetitivas,Test Driven Development (TDD), Continous Integration e Continous Delivery.

\subsection{Pós-Sabadágil e Nota Cruzada}

O principal objetivo do critério Pós-Sabadágil é avaliar o software desenvolvido pelos alunos durante o Sabadágil. Nesse momento, os professores e os alunos dos outros grupos desempenham o papel de usuários finais. A nota é a média das notas atribuídas pelos professores e pelos outros grupos. Eles buscam evidências que comprovem: 1) que o MVP foi implementado; 2) que o grupo utilizou ferramentas que os auxiliem a garantir a qualidade do produto como versionamento, integração contínua e testes automatizados; 3) que o layout e design da aplicação é de fácil compreensão para usuários finais; 4) implementação das métricas descritas na subseção 3.5 .

Cada professor e cada grupo apresenta as notas atribuídas a cada grupo em uma seção de Revisão e Retrospectiva conforme descrito no framework Scrum [3]. Isso é feito não só com o objetivo de rever essas duas práticas ágeis, como também aprimorar valores e princípios ágeis de transparência, feedback constante e melhoria contínua vistos durante o curso.

A Nota Cruzada é muito semelhante à nota Pós-Sabadágil. A única diferença é que nesse critério, cada grupo avalia o trabalho do outro grupo. O objetivo desse critério é fazer com que os alunos sejam capazes de identificar e avaliar atributos de software compatíveis com os princípios ágeis como simplicidade, feedback constante, alta qualidade, etc.

\subsection{Minutagem}

Como pode ser visto nas subseções 3.3 e 3.2, os professores procuram dividir cada aula em partes prática, teórica e de reflexão, sempre respeitando o conceito de Timebox [3] em que cada etapa da aula respeita uma quantidade fixa de tempo que não deve ser ultrapassada. Portanto, o sucesso da disciplina depende da presença e pontualidade de todos os alunos. Não faltar e chegar no horário é essencial para que eles, individualmente e coletivamente, tenham um bom aproveitamento da disciplina.

Para estimular os alunos a serem pontuais e participem das aulas, os professores definiram que um percentual da nota deles seria dado pelo tempo que eles permanecem em sala de aula. Tradicionalmente isso seria feito através da lista de chamada dos alunos realizada no início da aula, porém esse tipo de controle é contrário à filosofia Ágil e foi descartado pelos professores. Então, com o intuito de promover a disciplina do aluno, além do respeito não só ao grupo, como também aos alunos que não conseguiram ser aprovados na seleção descrita na subseção 3.1, foi desenvolvida a Minutagem. Ela é implementada através de uma 
planilha disponibilizada no Google Drive onde o próprio aluno informa a hora que ele chegou na aula. O intuito é gerar um ambiente confortável, de confiança mútua, que motive os alunos a participar ativamente das aulas além de trabalhar aspectos culturais da agilidade como responsabilidade, confiança na equipe e respeito ao próximo.

No dia da aula, os professores abrem a planilha de Minutagem às 07:45, quinze minutos antes do horário de início. Ela permanece aberta para edição até o final de cada aula. Durante todo esse tempo, cada aluno deve acessar a planilha e informar o horário que ele chegou. Em algumas aulas, o gráfico de Minutagem coletivo é exposto com o objetivo de fazer com que os alunos percebam o quanto eles estão aproveitando o tempo de aula, além de estimular o compromisso com o horário e evitar a perda de práticas e conteúdos importantes.

\subsection{Autoavaliação e Avaliação 360 ${ }^{\circ}$}

A Autoavaliação, como o próprio nome diz, é realizada pelos alunos individualmente. Nela cada indivíduo deve dizer como foi seu desempenho durante a matéria. Os professores não interferem nessa nota, geralmente os alunos utilizam alguns critérios comuns para se autoavaliar. Por exemplo, a dedicação dele durante o período, o conhecimento que ele adquiriu sobre métodos ágeis, participação nas aulas, colaboração com o grupo e com alunos em outros grupos, entre outros.

O princípio ágil da transparência é aplicado nesse critério de avaliação par evitar que alunos que pouco colaboraram se deem notas altas e também que alunos que são muito exigentes com seu próprio desempenho se sabotem dando notas baixas para eles mesmos, as notas são lançadas em uma planilha eletrônica compartilhada entre todos os alunos no Google Drive. Os professores não fazem nenhuma crítica ou alteração na nota lançada.

A Avaliação $360^{\circ}$ é uma nota onde cada membro do grupo deve aliar os demais membros e por eles ser avaliado. Essa nota busca evidenciar quais os participantes se dedicaram mais ao trabalho durante o semestre. Mais uma vez não há interferência dos professores nesse critério. Para reforçar ainda mais os valores e princípios de transparência, feedback constante e melhoria contínua, a nota é apresentada em uma seção de retrospectiva e informada na planilha eletrônica no Google Drive.

\subsection{Distribuição dos Pesos e Melhoria Contínua dos Critérios}

A nota final de cada aluno é a média ponderada de cada um dos critérios supracitados. Cada grupo, no final do curso, define qual o peso que eles darão para cada critério. Os professores também definem um peso para cada critério. O peso final é a soma de cada peso atribuído. A tabela 2 apresenta a distribuição de pesos feita pela turma do primeiro semestre de 2014. 


\begin{tabular}{|l|r|r|r|r|r|}
\hline & \multicolumn{3}{|c|}{ Grupos } & \\
\hline \multicolumn{1}{|c|}{ Critério } & Caronas & Joga Fácil & Tô na Fila & Professores & Peso Final \\
\hline Pré-Sabadágil & 0,6 & 0,75 & 0,3 & 0,5 & 2,15 \\
\hline Sabadágil & 0,7 & 0,75 & 0,4 & 0,5 & 2,35 \\
\hline Pós-Sabadágil & 0,2 & 0,1 & 0,5 & 0,2 & 1,00 \\
\hline Minutagem & 0,35 & 0,3 & 0,1 & 0,5 & 1,25 \\
\hline Autoavaliação & 0,2 & 0,2 & 0,4 & 0,3 & 1,10 \\
\hline Avaliação 360 & 0,35 & 0,3 & 0,3 & 0,3 & 1,25 \\
\hline Nota Cruzada & 0,1 & 0,1 & 0,5 & 0,2 & 0,90 \\
\hline Total & 2,5 & 2,5 & 2,5 & 2,5 & 10,00 \\
\hline
\end{tabular}

Tabela 2: Distribuição de Pesos dado pelos grupos e professores na turma do $1^{\circ}$ período de 2014.

Os professores acreditam que é essencial realizar a melhoria contínua da disciplina e, portanto, os critérios acima citados passaram a ser utilizados a partir de 2013. Antes disso, os professores davam uma nota de participação para cada aluno. A partir de 2013, baseado na experiência do Laboratório de XP da USP [10] e buscando desenvolver aspectos culturais como responsabilidade, ética e autoconhecimento, a nota de participação foi descontinuada e foram criadas a nota de Autoavaliação e a Avaliação $360^{\circ}$.

\section{Hipótese da Pesquisa}

A hipótese desse trabalho é: O Método é capaz de construir um ambiente colaborativo, estimulante e desafiador e com isso contribuir com a construção de conhecimento aplicável à futura vida profissional dos alunos?

Os objetivos específicos utilizados para avaliar a hipótese são: 1 . O aluno retém o conhecimento sobre Métodos Ágeis após o término do curso [23,24]. 2. A disciplina provê conhecimento aplicado para os futuros profissionais [28]. 3. Do ponto de vista dos alunos, o método de ensino utilizado é estimulante e divertido de forma que eles não só gostam de cursá-la, como também também a recomendam para outros alunos [26]. 4. Apresentar a taxa de abandono e reprovação do curso [24].

\section{Método da Pesquisa}

Esse estudo é uma Pesquisa Social que busca quantificar os dados e generalizar os resultados para a população de interesse [41]. Ela foi realizada de forma estruturada através 
do Método de Questionário submetido para todos os ex-alunos da disciplina [42].

Esse método de pesquisa é indicado por Chaer et al. [43] para realizar pesquisas educacionais. O Questionário possibilita atingir grande número de pessoas, mesmo que estejam dispersas; implica menores gastos com pessoal; garante o anonimato das respostas; permite que as pessoas o respondam no momento em que julgarem mais conveniente; e não expõe os pesquisadores à influência das opiniões e do aspecto pessoal do entrevistado [41].

Custer [44] também corrobora com o modelo de questionário de múltipla escolha para avaliação da retenção do conhecimento.

Os autores apresentam também as desvantagens de utilizar esse método, dentre eles: impede o auxílio ao informante quando este não entende corretamente as instruções ou perguntas; impede o conhecimento das circunstâncias em que foi respondido, o que pode ser importante na avaliação da qualidade das respostas; não oferece a garantia de que a maioria das pessoas devolva-o devidamente preenchido, o que pode implicar a significativa diminuição da representatividade da amostra; envolve, geralmente, número relativamente pequeno de perguntas, porque é sabido que questionários muito extensos apresentam alta probabilidade de não serem respondidos; e proporciona resultados bastante críticos em relação à objetividade, pois os itens podem ter significados diferentes para cada sujeito pesquisado [41].

Buscando minimizar os riscos de aplicação do método, um processo iterativo e incremental foi utilizado para a construção do questionário. Foram desenvolvidas cinco versões do mesmo e em cada uma, um ex-aluno era convidado a fornecer além da resposta, o feedback sobre o mesmo.

A primeira versão do questionário possuía 3 perguntas que buscavam definir o perfil do respondente e 4 perguntas abertas que buscavam descobrir o quanto o aluno se recordava sobre as aulas de Métodos Ágeis. Um aluno do $1^{\circ}$ período de 2012 foi selecionado para responder o questionário. Após respondê-lo, ele fez uma série de críticas e sugestões. Com base no resultado desse processo e pela dificuldade que seria tabular e analisar perguntas abertas, foi decidido que o questionário passaria a contar com perguntas fechadas, cada uma relacionada a um item de aprendizagem apresentado durante a disciplina.

A segunda versão do questionário contou com 5 perguntas para definir o perfil do respondente e 104 perguntas fechadas, uma para cada item de aprendizado apresentado em sala de aula. Para cada pergunta, o respondente poderia optar por uma das três opções de respostas: Lembro; Lembro mais ou menos; Não Lembro. Foi selecionado outro aluno do $1^{\circ}$ período de 2012 para responder esse questionário e fazer críticas e sugestões.

A terceira versão do questionário contou com as 8 perguntas para definição do perfil e 104 para avaliação do conhecimento. Para cada pergunta o respondente poderia optar por uma das respostas: Não lembro de ver isso em sala de aula; Lembro mais ou menos; Lembro, 
mas não uso; Lembro e uso. Foi selecionado um aluno do $1^{\circ}$ período de 2013 para responder esse questionário e fazer críticas e sugestões.

A quarta versão do questionário contou com 9 perguntas para identificar o perfil do respondente e 92 perguntas fechadas para avaliar o conhecimento. A redução no número de perguntas teve como objetivo: reduzir o tamanho do questionário, abranger apenas os itens de aprendizagem comum a todas as turmas entre 2011 e 2014 e remover perguntas de difícil compreensão.

A quinta versão do questionário foi elaborada à luz das diferentes observações apresentadas por Cohen et al. [45]. O novo questionário foi enviado para os três alunos que haviam respondido as outras versões de testes e mais um aluno ex-aluno do $1^{\circ}$ período de 2014. Mais uma vez, eles forneceram feedback muito positivo sobre as perguntas. O questionário enviado por e-mail para os ex-alunos era composto de 9 perguntas para identificação de perfil e 91 perguntas fechadas sobre a avaliação do conhecimento. Para cada pergunta de avaliação do conhecimento, o respondente poderia optar por uma das respostas: Desconheço; Ouvi falar, mas não sei do que se trata; Conheço mais ou menos; Conheço, mas não uso; Conheço e uso no meu cotidiano.

Os resultados aqui apresentados são analisados qualitativamente com o objetivo de prover indícios de que as hipóteses são válidas [46].

\subsection{Ameaças à validade do estudo}

As ameaças a este estudo são vistas à luz do trabalho de Campbell e Stanley [47]. Segundo os autores, nesse tipo de estudo é comparar o Método de Ensino aplicado a grupos focais e de controle. Infelizmente, a disciplina de Métodos Ágeis é oferecida apenas uma vez por ano sempre pelos mesmos professores. Não foi possível aplicar esse estudo a um grupo de controle para realizar uma avaliação quantitativa e comparativa. Também não foi possível encontrar informações históricas sobre a disciplina antes da implementação do método para servir como controle.

É importante ressaltar que na pesquisa sobre o Estado da Arte foi possível perceber que grande parte dos estudos nessa área apenas apresentam Métodos de Ensino baseados em Métodos Ágeis. Uma minoria dos estudos preocupa-se com a validação do método. Desses, não há um conjunto comum de variáveis a ser avaliada.

Também não foi possível controlar variáveis importantes com relação à manutenção do conhecimento ao longo do tempo. Os ex-alunos tiveram outras formas de contato com Métodos Ágeis seja em cursos, na vida pessoal ou profissional. Isso representa uma ameaça à validade histórica [47], porém é um sinal que o conhecimento apresentado é de alguma forma útil para os desenvolvedores de software. 
Além disso, embora o Método de Ensino já seja aplicado há mais de cinco anos com diversas turmas, os professores da disciplina foram sempre os mesmos. Isso representa um possível viés da pesquisa em que os grupos avaliados são diferentes, porém os facilitadores são sempre os mesmos. É difícil distanciar o quanto a performance pessoal dos professores interfere na disciplina.

\section{Resultado}

\subsection{Taxa de Resposta e Confiabilidade}

A Tabela 3 exibe a taxa de respostas do questionário por período. As colunas representam: período em que os alunos cursaram a disciplina; quantidade de alunos que concluíram o curso por período; relação entre a quantidade de alunos na turma e a quantidade de respostas esperadas para a turma; e a relação entre quantidade de respostas por turma sobre a quantidade total de respostas.

\begin{tabular}{|c|r|r|r|r|}
\hline Período & Qtd. Alunos & Respostas & Respostas / Alunos & Período / Respostas \\
\hline $\mathbf{2 0 1 1 . 1}$ & 26 & 9 & $34,61 \%$ & $20,00 \%$ \\
\hline $\mathbf{2 0 1 1 . 2}$ & 14 & 4 & $28,57 \%$ & $8,89 \%$ \\
\hline $\mathbf{2 0 1 2 . 1}$ & 20 & 10 & $45,00 \%$ & $20,00 \%$ \\
\hline $\mathbf{2 0 1 3 . 1}$ & 23 & 12 & $52,17 \%$ & $26,67 \%$ \\
\hline $\mathbf{2 0 1 4 . 1}$ & 17 & 11 & $64,70 \%$ & $24,44 \%$ \\
\hline Total & 100 & 46 & & $100,00 \%$ \\
\hline
\end{tabular}

Tabela 3: Taxa de respostas

Para estimar a confiabilidade do questionário, os dados foram submetidos ao Coeficiente Alfa de Cronbach [48] através da ferramenta IBM SPSS Statistics <http://www-01.ibm. $\mathrm{com} / \mathrm{software} / \mathrm{br} /$ analytics/spss/>. Foram analisadas as 91 perguntas fechadas sobre a avaliação do conhecimento e os 46 questionários respondidos. O coeficiente $\alpha$ é igual a 0,924 o que é considerado um nível alto de confiabilidade [45]. Maior do que o apresentado por Kamat e Sardessai [24].

\subsection{Retenção de Conhecimento}

Para avaliar a retenção do conhecimento ao longo dos anos, o questionário contou com 91 perguntas que versaram sobre os itens de aprendizagem apresentados em sala de aula. Para cada pergunta o respondente deveria informar se: a) Desconhecia o item; b) Havia ouvido falar sobre o item, mas não tinha certeza do que se tratava; c) Conhecia o item, 


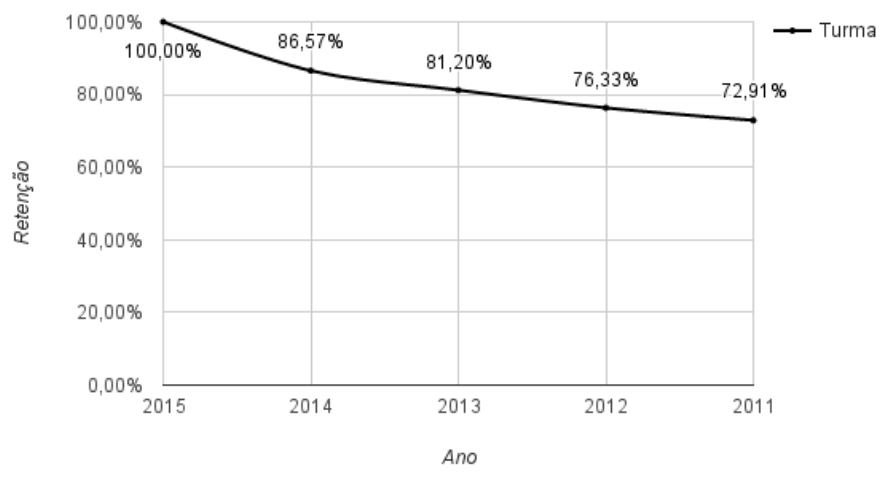

Figura 3: Curva de retenção de conhecimento dos respondentes.

porém não conseguiria explicá-lo; d) Conhecia o item, conseguiria explicá-lo, porém não utilizava em sua vida profissional; e) Conhecia o item, conseguiria explicá-lo e utilizava em sua vida profissional. A escolha das opções $\mathbf{a}, \mathbf{b}$ ou $\mathbf{c}$ indica que o respondente não reteve $o$ conhecimento sobre o item de aprendizado. Já a escolha das opções d ou e indica a retenção do conhecimento sobre o item de aprendizagem.

Para melhor analisar a retenção do conhecimento, a Figura 3 apresenta a Curva de Retenção do Conhecimento [49] da turma ao longo dos anos. Essa curva descreve a perda do conhecimento ao longo do tempo (respostas $\mathbf{a}, \mathbf{b}$ ou $\mathbf{c}$ ). É esperado que o quanto mais antiga a turma, maior o esquecimento.

O ano de 2015 foi arbitrariamente representado por uma turma em um estágio inicial retendo $100 \%$ do conhecimento. Esse número é fictício, pois o esquecimento acontece minutos após a apresentação do item de aprendizagem [44].

\subsection{Aplicabilidade da Disciplina}

Para compreender se o conteúdo apresentado na disciplina é aplicável no ambiente de trabalho, os ex-alunos foram convidados a responder a seguinte pergunta: "Você utiliza algum Método Ágil no Seu trabalho? Sim ou Não. Caso afirmativo, qual?”. A Tabela 4 apresenta a utilização de Métodos Ágeis na vida profissional dos ex-alunos e o percentual de utilização dos itens de aprendizagem que foram apresentados em sala de aula após o curso. Esta informação é feita com base nos alunos que responderam o questionário sobre retenção 
do conhecimento com a opção e (Conhecia o item, conseguiria explicá-lo e utilizava em sua vida profissional).

\begin{tabular}{|l|r|c|r|r|r|}
\hline \multirow{2}{*}{ Turma } & \multicolumn{2}{|c|}{ Sim } & \multicolumn{2}{c|}{ Não } & \multirow{2}{*}{ Utilização } \\
\cline { 2 - 5 } & Qtde. & \multicolumn{1}{c|}{$\%$} & Qtde. & \multicolumn{1}{c|}{$\%$} & \\
\hline $\mathbf{2 0 1 1 . 1}$ & 6 & $66,67 \%$ & 3 & $33,33 \%$ & $27,16 \%$ \\
\hline $\mathbf{2 0 1 1 . 2}$ & 3 & $75,00 \%$ & 1 & $25,00 \%$ & $43,06 \%$ \\
\hline $\mathbf{2 0 1 2 . 1}$ & 8 & $80,00 \%$ & 2 & $20,00 \%$ & $44,00 \%$ \\
\hline $\mathbf{2 0 1 3 . 1}$ & 10 & $83,33 \%$ & 2 & $16,67 \%$ & $38,15 \%$ \\
\hline $\mathbf{2 0 1 4 . 1}$ & 9 & $81,82 \%$ & 2 & $18,18 \%$ & $47,27 \%$ \\
\hline Total / Médias & 36 & $78,26 \%$ & 10 & $21,74 \%$ & $39,93 \%$ \\
\hline
\end{tabular}

Tabela 4: Uso de Métodos Ágeis na vida profissional dos ex-alunos

\subsection{Ambiente de Aprendizado}

Outro objetivo que esse trabalho busca analisar é se o método de ensino aplicado desenvolve um ambiente estimulante e divertido de aprendizagem. Para tal, os alunos responderam a seguintes pergunta: "Como você classificaria a disciplina em relação às outras?". Além das opções apresentadas no Figura 4a, os respondentes poderiam informar também se a disciplina tinha sido uma das cinco piores ou a pior disciplina da graduação. Entretanto, essas opções não foram marcadas por nenhum dos respondentes. Outra pergunta relacionada a esse objetivo foi: "Você recomendaria essa disciplina eletiva para outros alunos da graduação? Sim ou Não". As respostas são apresentadas nas Figura 4b.

\subsection{Abandono e Reprovação}

Para essa etapa da pesquisa é interessante reforçar que foram seguidas as recomendações sobre ética apresentadas por Cohem et al. [45]. Os dados sobre abandono e reprovação foram acessados e contabilizados apenas pelo Professor titular da matéria que tem acesso de consulta ao sistema de registro e notas dos alunos na disciplina. Os demais pesquisadores tiveram acesso apenas aos totais de forma que não são capazes de identificar quais alunos abandonaram ou foram reprovados.

Em todos os períodos, nunca houve uma reprovação e apenas 3 alunos abandonaram a disciplina. A taxa de abandono média é de $0,03 \%$, menor do que 1 aluno por período. 


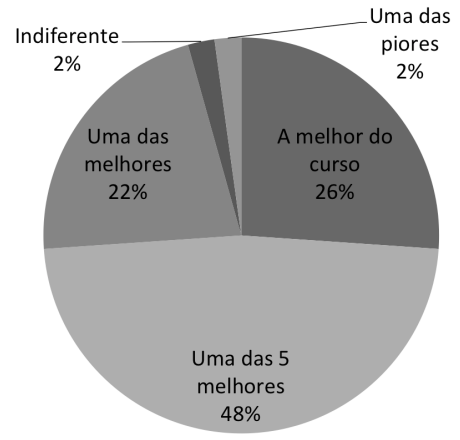

(a) Avaliação da disciplina

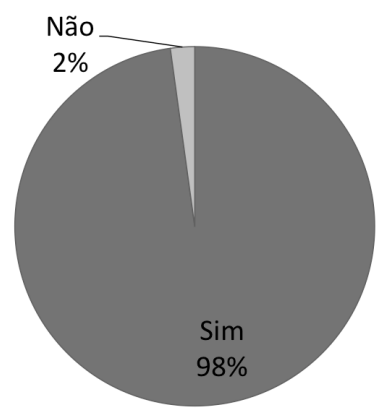

(b) Recomendaria a disciplina?

Figura 4: Gráficos contendo a avaliação da disciplina feita pelos respondentes.

\section{Conclusão}

O presente artigo procurou descrever a experiência utilizada pelos professores de Métodos Ágeis do Departamento de Ciências da Computação da Universidade Federal do Rio de Janeiro. Como eles utilizam valores e princípios dos Métodos Ágeis durante diversas etapas da disciplina. Além disso, ele apresentou uma avaliação qualitativa com os ex-alunos do curso. Essa avaliação procurou evidenciar a construção e utilidade do conhecimento e também a satisfação dos alunos em participar dessa disciplina.

Com relação às hipóteses apresentadas na Seção 5, assim como em estudos semelhantes [13,24,28], este provê indícios que um Método de Ensino baseado em Métodos Ágeis é capaz de gerar conhecimento. Conforme exposto na Subseção 7.2, os alunos recordamse de grande quantidade dos itens de aprendizagem apresentados em sala de aula durante o semestre.

Quanto à utilidade da disciplina, assim como no estudo de Kropp e Meier [28], é possível concluir que a disciplina provê conhecimento útil para os futuros profissionais de desenvolvimento de software. Mais de $78 \%$ dos respondentes utilizam Métodos Ágeis na sua vida profissional.

A pesquisa também corrobora com as avaliações feitas por Stettina et al. [26] e Grimheden [25]. Os alunos que utilizam as práticas ágeis durante a disciplina como base do processo de ensino e aprendizagem sentem-se satisfeitos com o ambiente proporcionado por essas práticas conforme apresentado na Subseção 7.4. 95\% dos respondentes avaliaram a disciplina como sendo uma das melhores do curso de graduação. Além disso, apresenta uma taxa de reprovação nula e uma taxa de abandono de apenas $3 \%$, um pouco maior do que àquela 
apresentada por Kamat e Sardessai [24].

Por fim, podemos concluir que há indícios de que o Método de Ensino aqui apresentado é capaz de gerar conhecimento útil em um ambiente de aprendizado estimulante para os futuros desenvolvedores de software.

\subsection{Trabalhos Futuros}

Seria interessante aplicar o Método de Ensino em outras universidades e outros professores para obter novos dados e tentar reduzir o viés do professor. Outra estratégia poderia ser utilizar e avaliar o Método de Ensino proposto em outras disciplinas de Engenharia de Software.

Também é importante observar e avaliar as próximas turmas, começando com a de 2015.1. Essa turma é recém terminada e, portanto, está menos propensa a sofrer o viés histórico. O acompanhamento dessa turma permite classificar o conhecimento construído de acordo com a Taxonomia de Bloom [39], o que não foi possível realizar nas turmas passadas.

Para um resultado mais generalizável, seria relevante aplicar as mesmas variáveis e comparar o Método de Ensino com outros métodos utilizados por outros professores de Métodos Ágeis e até mesmo de outras disciplinas.

\section{Referências}

1 BECK, K. et al. Manifesto for Agile Software Development. 2001. <http: //www.agilemanifesto.org/>.

2 ABBAS, N.; GRAVELL, A. M.; WILLS, G. B. Historical roots of agile methods: where did "agile thinking" come from? In: Agile Processes in Software Engineering and Extreme Programming. [S.1.]: Springer, 2008. p. 94-103.

3 SUTHERLAND, J.; SCHWABER, K. The Definitive Guide to Scrum: The Rules of the Game. <http://www.scrumguides.org/docs/scrumguide/v1/Scrum-Guide-US.pdf>: Scrum Guides, 2011.

4 Version One. 8th Annual State of Agile Survey. Alpharetta, GA, USA, 2013. 14 p. Disponível em: <http://www.versionone.com/pdf/2013-state-of-agile-survey.pdf>.

5 MELO, C. de O. et al. The evolution of agile software development in brazil. Journal of the Brazilian Computer Society, Springer London, v. 19, n. 4, p. 523-552, 2013. ISSN 0104-6500. 
6 FERNANDES, J.; SOUSA, S. Playscrum - a card game to learn the scrum agile method. In: Games and Virtual Worlds for Serious Applications (VS-GAMES), 2010 Second International Conference on. [S.1.: s.n.], 2010. p. 52-59.

7 GKRITSI, A. Scrum Game: An Agile Software Management Game. Tese (Doutorado) University of Southampton, September 2011.

8 WANGENHEIM, C. G. von; SAVI, R.; BORGATTO, A. F. Scrumia - an educational game for teaching scrum. Journal of Systems and Software, v. 86, n. 10, p. 2675 - 2687, 2013.

9 BECK, K. Extreme Programming Explained: Embrace Change. Boston, MA - EUA: Addison-Wesley, 2000. (An Alan R. Apt Book Series).

10 GOLDMAN, A. et al. Being Extreme in the Classroom: experiences Teaching XP. Journal of the Brazilian Computer Society, scielo, v. 10, p. 5 - 21, 112004.

11 CORBUCCI, H. et al. Genesis and evolution of the agile movement in brazil perspective from academia and industry. In: Software Engineering (SBES), 2011 25th Brazilian Symposium on. [S.1.: s.n.], 2011. p. 98-107.

12 TELES, V. M.; OLIVEIRA, C. E. T. de. Reviewing the curriculum of software engineering undergraduate courses to incorporate communication and interpersonal skills teaching. In: IEEE. Software Engineering Education and Training, 2003.(CSEE\&T 2003). Proceedings. 16th Conference on. [S.1.], 2003. p. 158-165.

13 ANDERSON, D. et al. Studying lean-kanban approach using software process simulation. In: Agile Processes in Software Engineering and Extreme Programming. [S.1.]: Springer, 2011. p. 12-26.

14 SUGIMORI, Y. et al. Toyota production system and kanban system materialization of just-in-time and respect-for-human system. The International Journal of Production Research, Taylor \& Francis, v. 15, n. 6, p. 553-564, 1977.

15 RIES, E. The Lean Startup: How Today's Entrepreneurs Use Continuous Innovation to Create Radically Successful Businesses. New York, NY - EUA: Crown Publishing Group, 2011.

16 WOOLFOLK, A.; WINNE, P.; PERRY, N. Social cognitive and constructivist views of learning. In: Educational Psychology. 11th. ed. Princeton, NC, EUA: Merrill, 2009. cap. 9, p. 312-347.

17 JOHNSON, R. T. J. D. W.; STANNE, M. B. Cooperative learning methods: A meta-analysis. Revista de Educação, São Paulo, SP, v. 15, n. 16, p. 3-16, 1936. 
18 BANDURA, A.; AZZI, R. G.; POLYDORO, S. A. Teoria Social Cognitiva: Conceitos básicos. Porto Alegre, RS: Artmed Editora, 2009.

19 KOLB, D. A.; BOYATZIS, R. E.; MAINEMELIS, C. Experential learning theory: Previous research and new directions. In: Perspectives on Thinking, Learning, and Cognitive Styles. 2nd. ed. Abingdon, OX - Inglaterra: Routledge, 2014. cap. 9, p. 227-248.

20 FELICIA, P. Handbook of Research on Improving Learning and Motivation through Educational Games: Multidisciplinary Approaches: Multidisciplinary Approaches. [S.1.]: Information Science Reference, 2011.

21 DEWEY, J. Experiência e educação (tradução de anísio teixeira). coleção cultura, sociedade. Educação, v. 15, 1971.

22 MOGILKA, M. Autonomia e formação humana em situações pedagógicas : um difícil percurso. Educação e Pesquisa, scielo, v. 25, p. 57 - 68, 071999.

23 KAMAT, V. Agile manifesto in higher education. In: Technology for Education (T4E), 2012 IEEE Fourth International Conference on. [S.1.: s.n.], 2012. p. 231-232.

24 KAMAT, V.; SARDESSAI, S. Agile practices in higher education: A case study. In: AGILE India (AGILE INDIA), 2012. [S.1.: s.n.], 2012. p. 48-55.

25 GRIMHEDEN, M. E. Can agile methods enhance mechatronics design education? Mechatronics, v. 23, n. 8, p. 967 - 973, 2013. ISSN 0957-4158.

26 STETTINA, C. et al. Academic education of software engineering practices: towards planning and improving capstone courses based upon intensive coaching and team routines. In: Software Engineering Education and Training (CSEE T), 2013 IEEE 26th Conference on. [S.1.: s.n.], 2013. p. 169-178. ISSN 1093-0175.

27 WILLEKE, M. Agile in academics: Applying agile to instructional design. In: Agile Conference (AGILE), 2011. [S.1.: s.n.], 2011. p. 246-251.

28 KROPP, M.; MEIER, A. Teaching agile software development at university level: Values, management, and craftsmanship. In: Software Engineering Education and Training (CSEE T), 2013 IEEE 26th Conference on. [S.1.: s.n.], 2013. p. 179-188. ISSN 1093-0175.

29 TELES, V. M. a. Um estudo de caso da adoção das práticas e valores do eXtreme Programming. 145 p. - Universidade Federal do Rio de Janeiro, 2005.

30 WOOD, D. F. Problem based learning. British Medical Journal, British Medical Journal, v. 326, n. 7384, p. 328-330, 2003. 
31 The Startup Machine. Validation Board. 2014. Disponível em: <https://www. leanstartupmachine.com/validationboard/>.

32 HOHMANN, L. Innovation Games: Creating Breakthrough Products Through Collaborative Play. New York, NY - EUA: Pearson Education, 2006.

33 COHN, M. User Stories Applied: For Agile Software Development. Boston, MA - EUA: Addison-Wesley, 2004.

34 BOLTON, M. K. The role of coaching in student teams: A "just-in-time" approach to learning. Journal of Management Education, Sage Publications, v. 23, n. 3, p. 233-250, 1999.

35 DELGADO, C. A. D. M.; TOLEDO, R. de; BRAGANHOLO, V. Uso de dojos no ensino superior de computação. In: Anais do WEI XX Workshop sobre Educação em Computação. [S.1.: s.n.], 2012.

36 BECK, K. Test-driven Development: By Example. 1st. ed. Boston, MA - EUA: Addison-Wesley, 2003.

37 ADKINS, L. Coaching Agile Teams: A Companion for ScrumMasters, Agile Coaches, and Project Managers in Transition. 1st. ed. New York, NY - EUA: Pearson Education, 2010.

38 MOORE, G. Crossing the Chasm: Marketing and Selling Disruptive Products to Mainstream Customers. New York, NY - EUA: HarperCollins, 2002.

39 FERRAZ, A. P. d. C. M.; BELHOT, R. V. Taxonomia de Bloom: revisão teórica e apresentação das adequações do instrumento para definição de objetivos instrucionais. Gestão \& Produção, scielo, v. 17, p. 421 - 431, 2010.

40 TOLEDO, R. Até onde vai a agilidade? Knowledge 21, 2014. Disponível em: $<$ http://www.knowledge21.com.br/ate-onde-vai-agilidade/>.

41 GIL, A. C. Métodos e técnicas de pesquisa social. $6^{\mathrm{a}}$. ed. São Paulo, SP: Atlas, 2008. $216 \mathrm{p}$.

42 MAlhotra, N. Pesquisa de Marketing: Uma Orientação Aplicada. 6a. ed. Porto Alegre, RS: Bookman, 2012.

43 CHAER, G.; DINIZ, R. R. P.; RIBEIRO, E. A. A técnica do questionário na pesquisa educacional. Revista Evidência, v. 7, n. 7, 2012.

44 CUSTERS, E. Long-term retention of basic science knowledge: a review study. Advances in Health Sciences Education, Springer Netherlands, v. 15, n. 1, p. 109-128, 2010. 
45 COHEN, L.; MANION, L.; MORRISON, K. Research Methods in Education. Abingdon, OX - Inglaterra: Routledge, 2013.

46 DIAS, D. de S.; SILVA, M. da. Como escrever uma monografia: manual de elaboração com exemplos e exercícios. São Paulo, SP: Atlas, 2010.

47 CAMPBELL, D. T.; STANLEY, J. C.; GAGE, N. L. Experimental and quasiexperimental designs for research. Boston, MA - EUA, 1963.

48 CRONBACH, L. J. Coefficient alpha and the internal structure of tests. psychometrika, Springer, v. 16, n. 3, p. 297-334, 1951.

49 EBBINGHAUS, H. Über das gedächtnis: untersuchungen zur experimentellen psychologie. [S.1.]: Duncker \& Humblot, 1885. Tradução em inglês disponível no site da Universidade de York, Ontário, Canadá <http://psychclassics.yorku.ca/Ebbinghaus/index. htm>. Acessado em abril de 2015. 